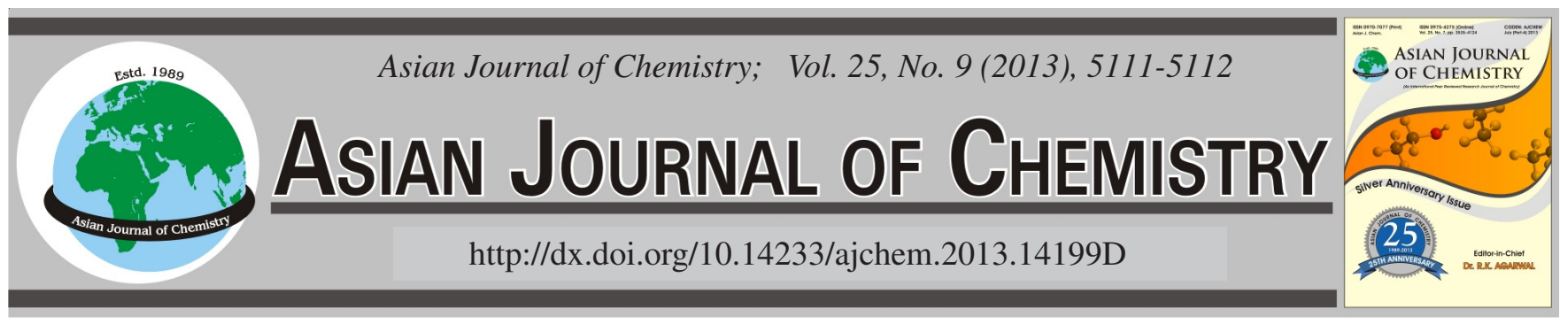

NOTE

\title{
Anticonvulsant Potential of Essential Oil of Vetiveriazizanioides Linn. Nash
}

PraVEen Kumar ${ }^{*}$ and Laxmi Tripathi

Department of Pharmaceutical Chemistry, S.D. College of Pharmacy and Vocational Studies, Muzaffarnagar-251 001, India

*Corresponding author: E-mail: praveensha77@yahoo.co.in

\begin{abstract}
In light of the traditional claim of south Indian tribes to use root and stem juice of Vetiveria zizanioides (Linn.) Nash in the treatment of epilepsy, an investigation was carried out to evaluate the anticonvulsant activity of essential oil obtained from the fresh roots and stem of V. zizanioides. The anticonvulsant activity was screened in maximal electroshock induced seizure (MES) and subcutaneous pentylenetetrazole induced seizure models in mice. The neurotoxicity was assessed using the rotorod method. Oil obtained from roots of $V$. zizanioides showed $100 \%$ protection in maximal electroshock induced seizures. But, no protection was observed in subcutaneous pentylenetetrazole induced seizures. Oil obtained from stems of V. zizanioides was inactive in both maximal electroshock and subcutaneous pentylenetetrazole induced seizures. No neurotoxicity was observed at the highest administered dose. Thus, the present study has demonstrated that the essential oil present in roots of $V$. zizanioides has anticonvulsant properties.
\end{abstract}

Key Words: Anticonvulsant activity, Vetiveriazizanioides Linn. Nash.

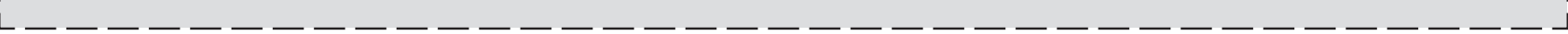

Vetiveria zizanioides (Linn.) Nash (Poaceae), popularly known as khus grass, has been known in India since ancient times. Khus grass grows wild in many states, namely Haryana, Uttar Pradesh, Rajasthan, Gujarat, Bihar, Orissa, Madhya Pradesh and throughout south India. Two species of Vetiveria are found in India, of which V. zizanioides is the common source of the well known oil of vetiver, which is used in medicine and in perfumery ${ }^{1}$. The grass has been reported to have antimycobacterial ${ }^{2}$, antibacterial ${ }^{3}$, antipyretic ${ }^{4}$, antioxidant $^{5}$, larvicidal, repellent and insecticidal properties ${ }^{6}$. Various tribes use different parts of the grass for many of their ailments such as mouth ulcer, fever, boil, epilepsy, burn, snakebite, scorpion sting, rheumatism, fever, headache, etc. The Santhal tribes of Bihar and West Bengal use the paste of fresh roots for burn, snakebite and scorpion sting and a decoction of the roots as a tonic for weakness. The Lodhas tribes of West Bengal use the root paste for headache, rheumatism and sprain and a stem decoction for urinary tract infection; the Mandla and Bastar tribes of Madhya Pradesh use the leaf juice as anthelmintic; the tribes of the Varanasi district inhale the root vapour for malarial fever. The root ash is given to patients for acidity by the Oraon tribe. Likewise, there are many different applications of the plant for different ailments among different ethnic tribes. South Indian tribes use leaf paste of khus grass in rheumatism and sprain and root and stem juice in boil, burn, epilepsy, scorpion sting, snakebite and mouth ulcer $^{7,8}$.

Thus, there are traditional evidences for the use of root and stem juice of $V$. zizanioides in epilepsy, but this activity has not yet been established experimentally. Essential oil is reported to be present in the roots of $V$. zizanioides ${ }^{9}$. As essential oils present in plants are shown to be responsible for the anticonvulsant activity of the plant ${ }^{10}$. An attempt was made to evaluate the anticonvulsant potential of essential oil obtained from fresh roots and stems of $V$. zizanioides. The anticonvulsant activity was screened in maximal electroshock induced seizure (MES) and subcutaneous pentylenetetrazole (scPTZ) induced seizure models in mice. The neurotoxicity was assessed using the rotorod method.

The roots and stem of $V$. zizanioides were collected from the local market of Muzaffarnagar and authenticated in the Department of Pharmacognosy, S. D. College of Pharmacy \& Vocational Studies, Muzaffarnagar, India. A voucher specimen (PK-112) has been deposited in the herbarium.

Preparation of extract: The fresh roots and stems were grounded in a blender. The grounded material was subjected to hydrodistillation using a Clevenger apparatus for $4 \mathrm{~h}$ for isolation of oil (Oil of roots of $V$. zizanioides: ROVZ: $2.0 \%$ v/w; Oil of stem of $V$. zizanioides: SOVZ: $0.8 \% \mathrm{v} / \mathrm{w})$. The essential oil was diluted with sesame oil to obtain the desired 
TABLE 1

ANTICONVULSANT AND NEUROTOXIC ACTIVITY OF OIL OF ROOTS OF $V$. zizanioides (ROVZ); OIL OF STEM OF $V$. zizanioides (SOVZ)

\begin{tabular}{|c|c|c|c|c|c|c|}
\hline \multirow{3}{*}{ Compound } & \multicolumn{6}{|c|}{ Intraperitoneal injection in mice $^{*}$} \\
\hline & \multicolumn{2}{|c|}{ MES screen $(\mathrm{h})$} & \multicolumn{2}{|c|}{ scPTZ screen $(\mathrm{h})$} & \multicolumn{2}{|c|}{ Neurotoxicity screen (h) } \\
\hline & 0.5 & 4.0 & 0.5 & 4.0 & 0.5 & 4.0 \\
\hline ROVZ & - & $300 * *$ & - & - & - & - \\
\hline SOVZ & - & - & - & - & - & - \\
\hline Phenytoin & 30 & 30 & - & - & 100 & 100 \\
\hline Sodium valproate & - & - & - & 300 & - & - \\
\hline
\end{tabular}

doses and was immediately administered intraperitoneally (i.p.) to mice.

Anticonvulsant and neurotoxicity evaluation: The animal study was carried out according to the protocols approved by the Institutional Animal Ethical Committee, S.D. College of Pharmacy and Vocational Studies, Muzaffarnagar (Reg No. 876/AC/05/CPCSEA). Male albino mice (CF-1 strain, 18-25 g) were used as experimental animals. The animals were housed in metabolic cages and allowed free access to food and water. In the preliminary screening each compound was administered as an i.p. injection at three dose levels (30, 100 and $300 \mathrm{mg} / \mathrm{kg}$ ) and anticonvulsant and neurotoxic effects were assessed at $0.5 \mathrm{~h}$ and $4 \mathrm{~h}$ intervals after administration. Anticonvulsant efficacy was measured by maximal electroshock induced seizure and subcutaneous pentylenetetrazole tests.

Essential oils are present in the roots and stem of $V$. zizanioides. The essential oil in the roots (ROVZ) is thick and dark brown in colour. The oil distilled from the stem (SOVZ) is inferior in quantity and quality from that obtained from roots.

ROVZ and SOVZ were evaluated for anticonvulsant activity in maximal electroshock induced seizure (MES) and subcutaneous pentylenetetrazole induced seizure models in mice using doses of $30,100,300 \mathrm{mg} / \mathrm{kg}$. The observation was carried out at two different time intervals $(0.5$ and $4 \mathrm{~h})$. The pharmacological test results are shown in Table-1. ROVZ showed $100 \%$ protection $(1 / 1,4.0 \mathrm{~h})$ at a dose of $300 \mathrm{mg} / \mathrm{kg}$ in maximal electroshock induced seizure test, indicating the compounds ability to prevent seizure spread. But, ROVZ showed no protection in subcutaneous pentylene-tetrazole induced seizures. SOVZ is inactive in both maximal electroshock induced seizure and subcutaneous pentylenetetrazole induced seizures. Both ROVZ and SOVZ exhibited no neurotoxicity at the highest administered dose $(300 \mathrm{mg} / \mathrm{kg})$ in rotorod method. Thus, the present study has demonstrated that the essential oil present in roots of $V$. zizanioides has anticonvulsant properties. Advanced anticonvulsant screening and mechanistic studies are required to further explore the anticonvulsant activity of roots of $V$. zizanioides.

\section{REFERENCES}

1. R.R. Rao and M.R. Suseela, Proceedings of Second International Conference on Vetiver. Office of the Royal Development Projects Board, Bangkok, pp. 444-448 (2000)

2. J.A. Hammond, D. Fielding and S.C. Bishop, Vet. Res. Com., 21, 213 (1997).

3. R.D. Vidyarthi, A Text Book of Zoology, S. Chand \& Co., New Delhi, edn. 14 (1967).

4. O. Ajaiyeoba, P.A. Onocha and O.T. Olarenwaju, Pharm. Biol., 39, 217 (2001).

5. Y.M. Shivkumar and V.L. Kumar, Pharma Biol., 41, 263 (2003).

6. A.A Gbolade and A.A. Adeyemi, Fitoterapia, 79, 200 (2008).

7. S.K. Jain, Dictionary of Indian Folk Medicine and Ethnobotany. Deep Publ., New Delhi, India (1991).

8. K.K. Singh and J.K. Maheshwari, J. Econ. Tax. Bot., 4, 829 (1983).

9. N.I. Bhuiyan, J.U. Chowdhury and J. Begum, Bangladesh J. Bot., 37, 213 (2008)

10. R.N. Almeida, M.F. Agra, F.N.S. Maior and D.P. DeSousa, Molecules, 16, 2726 (2011). 